\title{
The prevalence of rheumatoid arthritis in middle-aged and elderly people living in Naqu City, Tibet, Autonomous Region of China
}

Qingxi Zhang ${ }^{1,2}$, Qiang Liu ${ }^{1,2}$, Chutong Lin ${ }^{1,2}$, Yangjin Baima ${ }^{3}, \mathrm{Hu} \mathrm{Li}^{1,2}$, Hongqiang Gong ${ }^{4^{*}}$ and Jianhao Lin ${ }^{1,2^{*}}$ (D)

\begin{abstract}
Objective: To estimate the prevalence of rheumatoid arthritis (RA) in the Tibet Autonomous Region (China). Methods: A population-based cross-sectional survey was conducted on 1458 residents of Luoma Town, Tibet Autonomous Region, who were aged $\geq 40$ years old. We interviewed participants using questionnaires, and rheumatoid factor (RF), anti-citrullinated protein antibodies (ACPA), and C-reactive protein (CRP) were determined. The identification of RA in this study was on the basis of criteria issued by the 2010 American College of Rheumatology/European League Against Rheumatism (ACR/EULAR) guideline.
\end{abstract}

Results: Herein, 782 participants completed all items of RA. The overall prevalence of RA was $4.86 \%$, and the prevalence was higher in women than that in men $(7.14 \%$ vs. $2.56 \%, p=0.005)$. The age-standardized prevalence of RA was 6.30\% (95\% confidence interval (Cl) $4.20-8.64 \%)$, which was $2.46 \%(95 \% \mathrm{Cl} 1.04 \%, 4.10 \%)$ and $9.59 \%(95 \% \mathrm{Cl}$ $5.93 \%, 13.77 \%)$ in men and women, respectively.

Conclusion: The prevalence of RA is relatively higher in the Tibet than that in other areas of China.

Keywords: Rheumatoid arthritis, Tibet, High altitude

\section{Introduction}

Rheumatoid arthritis (RA) is a chronic systematic autoimmune inflammatory disease characterized by a symmetrical inflammatory polyarthritis of the joints of the hands, wrist, feet, and knee, which may result in joint swelling, pain, stiffness, and possible loss of function [1]. It seriously affects the life quality of patients. As reported previously, women are at a higher risk of RA than men, with the highest prevalence among women aged

\footnotetext{
*Correspondence: rockyghq@126.com; linjianhao@pkuph.edu.cn

${ }^{4}$ Tibet Center for Disease Control and Prevention, No. 21, North Linkuo Road, Chengguan District, Lhasa City 850000, Tibet Autonomous Region Tibet, China

${ }^{1}$ Arthritis Clinic \& Research Center, Peking University People's Hospital, Peking University, 11th Xizhimen South Street, Beijing, China

Full list of author information is available at the end of the article
}

over 65 years [2]. Almost 20 million people were living with RA in 2017 globally, with over one million new cases diagnosed each year, according to estimates from the Global Burden of Diseases, Injuries, and Risk Factors (GBD) Study [3]. However, due to the different geographic and demographic factors, the prevalence of RA is different in a variety of regions. The disease is more common in northern Europe and North America, while it is scarcely reported in the developing countries [4].

In China, the first epidemiological study on RA was not reported until 1983, with a prevalence of $0.3 \%$ in Taiwan [5]. Several epidemiological researches conducted across China mainland were published, and it was shown that the prevalence of RA ranges from 0.2 to $0.93 \%$ in China [6]. However, China is a vast country

C C The Author(s). 2020 Open Access This article is licensed under a Creative Commons Attribution 4.0 International License, which permits use, sharing, adaptation, distribution and reproduction in any medium or format, as long as you give appropriate credit to the original author(s) and the source, provide a link to the Creative Commons licence, and indicate if changes were made. The images or other third party material in this article are included in the article's Creative Commons licence, unless indicated otherwise in a credit line to the material. If material is not included in the article's Creative Commons licence and your intended use is not permitted by statutory regulation or exceeds the permitted use, you will need to obtain permission directly from the copyright holder. To view a copy of this licence, visit http://creativecommons.org/licenses/by/4.0/ The Creative Commons Public Domain Dedication waiver (http://creativecommons.org/publicdomain/zero/1.0/) applies to the data made available in this article, unless otherwise stated in a credit line to the data. 
with gradual altitude decreasing from the western to the eastern areas [7]. To our knowledge, there are few concerns about the prevalence of RA in Western China, especially Tibet. Since the 18th National Congress of the Communist Party of China, the alleviation of poverty in China has made a remarkable progress. Medical aid for Tibet Autonomous Region is of great significance. The People's Republic of China gives top priority to the improvement of Tibetan's livelihoods. However, collection of epidemic data and making clinical decisions are very difficult due to the widely distributed population of Tibet across high mountain areas [8]. Therefore, conducting further study is essential and urgent with the aim of describing the prevalence of RA in Tibet area.

\section{Subjects and methods Subjects}

This was a cross-sectional survey and the target population was participants who were aged $\geq 40$ years old and were residents of the Tibet. Luoma Town was randomly selected from 12 towns in Seni Community, Naqu City, Tibet, China. Luoma Town was located in northern Tibet with an average altitude above $4500 \mathrm{~m}$. In the current study, first, one community was randomly selected from Naqu City. Next, one town was randomly selected from the former community. The cluster (Luoma Town) covered 12 villages, and all households in the cluster were included in this study. All inhabitants, who were aged $\geq 40$ years old and were self-described residents of Luoma Town, were included. Individuals who had disability, mental disorders, and malignant tumors, and lived away from home for more than half a year were excluded from the survey. The survey was approved by the Ethics Committee of Peking University Health Science Center (Beijing, China). Written informed consent was obtained from all participants, and the survey was conducted in accordance with the Declaration of Helsinki.

\section{Questionnaire}

The questionnaire was administered to health care professionals, as it was anticipated that several participants would be illiterate and could not speak mandarin. All interviewers and clinical examiners were trained under the supervision of principal investigators (Hongqiang Gong and Jianhao Lin). Sociodemographic characteristics (e.g., sex, age, levels of education) were queried.

Clinical and laboratory examinations and definition of RA Height was measured with a wall-mounted stadiometer using the average of two measurements taken. Body weight was assessed using a beam balance scale with 0.1 $\mathrm{kg}$ precision. Two professionals took history. Venous blood was collected from each consented respondent by medically trained staffs from the Chinese Center for
Disease Control and Prevention based on a standard protocol. The centrifuged blood samples were stored in a deep freezer in the local health station. After samples were fully collected, the blood-based bioassays were performed at Tibet Autonomous Region People's Hospital. We tested the rheumatoid factor (RF), anti-citrullinated protein antibodies (ACPA), and C-reactive protein (CRP). The RF and CRP levels were detected using turbidimetric inhibition immune-assay, and ACPA was determined using chemiluminescent immunoassay. RA was identified according to the criteria issued by the 2010 American College of Rheumatology/European League Against Rheumatism (ACR/EULAR) guideline [9].

\section{Statistical analysis}

Quantitative data were analyzed using EpiData software (EpiData Association, Odense, Denmark). We divided all subjects into four age-based groups (i.e., 40-49, 50-59, $60-69$, and $\geq 70$ years old). The levels of education were classified into elementary school and below, middle school, high school, and college and higher. All statistical analyses were performed using SPSS 22.0 software (IBM, Armonk, NY, USA). Continuous variables and categorical variables were expressed as mean \pm standard deviation (SD) and proportions, respectively. According to Chinese census population in 2010, the national average age was adopted as the standard and the direct method was used to calculate the standardized mortality rates in various conditions [10]. Quantitative variables were summarized as mean values and $95 \%$ confidence interval (CI). Differences between groups were analyzed by chisquare test or Fisher's exact test for categorical data, if appropriate. Univariate and multivariate logistic regression analyses were undertaken to estimate the odds ratio (OR) and CI of factors associated with RA occurrence. $p$ $<0.05$ was considered statistically significant.

\section{Results \\ Participants}

In this survey, 2088 subjects were recruited, who were aged $\geq 40$ years old, and 256 subjects were excluded due to aforementioned reasons. Finally, 1832 subjects were enrolled, and $1458(80 \%)$ subjects signed the written informed consent form and completed the survey between September and October 2018. The attended participants were younger than those who declined to participate $(52.30 \pm 8.43$ versus $58.5 \pm 3.42, p=0.106)$. Moreover, 782 participants completed all items of RA and attended in laboratory tests (Fig. 1). The sociodemographic characteristics of eligible participants are shown in Table 1. There was no significant difference between participants who took blood samples and those who refused to take blood samples, except for age-relevant characteristics. About half $(50.13 \%)$ of the included subjects were 


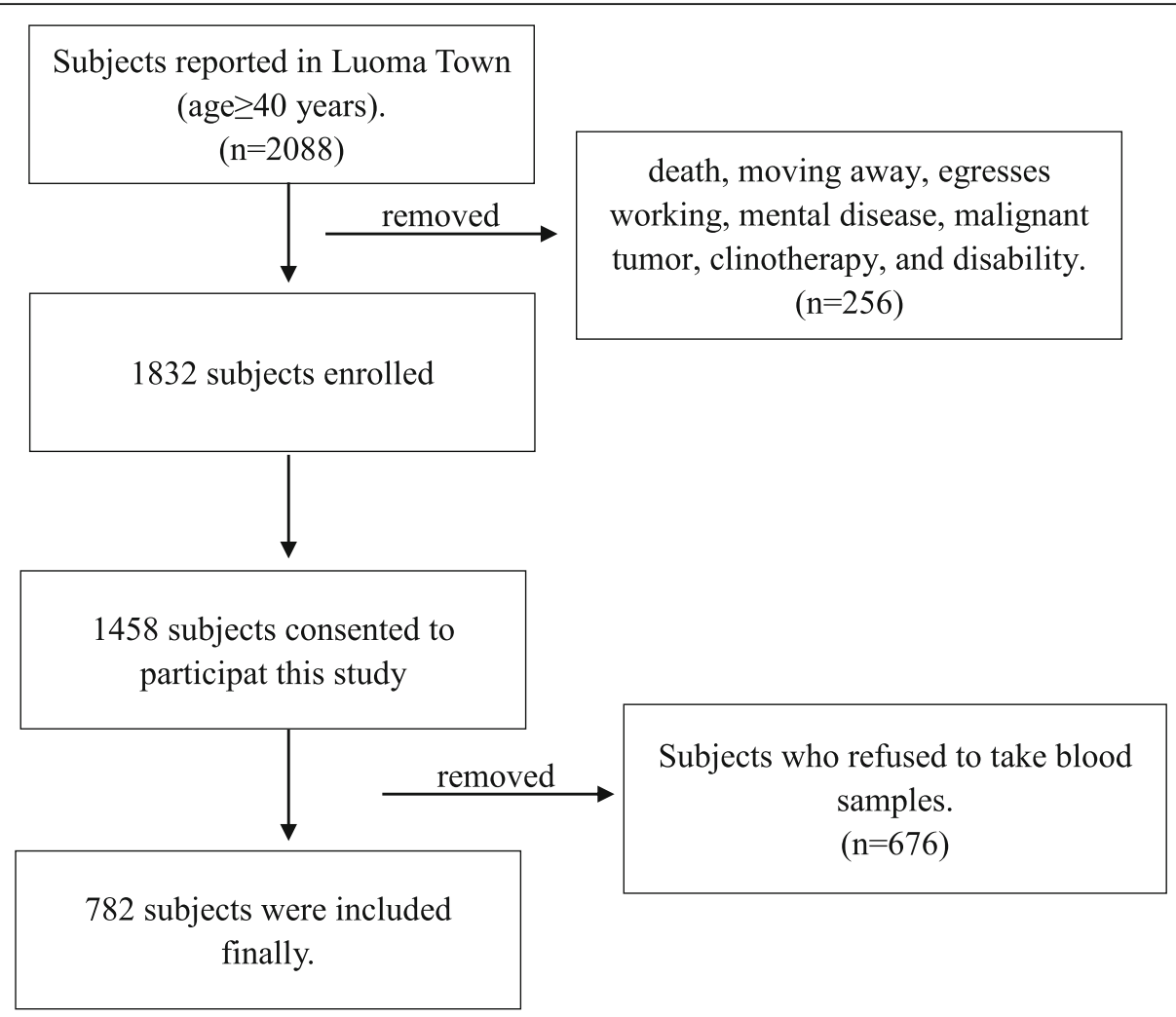

Fig. 1 Flowchart of subjects screening

Table 1 Sociodemographic characteristics of the subjects

\begin{tabular}{|c|c|c|c|c|c|c|}
\hline \multicolumn{4}{|c|}{ Subjects who consent to take blood samples } & \multicolumn{3}{|c|}{ Subjects who refused to take blood samples } \\
\hline & $\begin{array}{l}\text { Male } \\
49.87 \% \\
(n=390)\end{array}$ & $\begin{array}{l}\text { Female } 50.13 \%(n= \\
\text { 392) }\end{array}$ & Total(782) & $\begin{array}{l}\text { Male } 48.52 \%(n= \\
328)\end{array}$ & $\begin{array}{l}\text { Female } 51.48 \%(n= \\
348)\end{array}$ & Total(676) \\
\hline Age, mean $\pm S D$ & $\begin{array}{l}51.81 \pm \\
8.07\end{array}$ & $52.79 \pm 8.74$ & $\begin{array}{l}52.30 \pm \\
8.43\end{array}$ & $54.17 \pm 9.79$ & $53.47 \pm 10.24$ & $\begin{array}{l}53.81 \pm \\
10.0^{*}\end{array}$ \\
\hline \multicolumn{7}{|l|}{ Age group, \% (n) } \\
\hline $40-50$ & $41.87 \%(164)$ & $45.13 \%(176)$ & $43.48 \%(340)$ & $38.41 \%(126)$ & $44.54 \%(155)$ & $41.57 \%(281)$ \\
\hline $50-59$ & $36.99 \%(145)$ & $38.21 \%(149)$ & $37.60 \%(294)$ & $34.45 \%(113)$ & $29.89 \%(104)$ & $32.1 \%(217)$ \\
\hline $60-69$ & $16.58 \%(65)$ & $13.33 \%(52)$ & $14.96 \%(117)$ & $19.51 \%(64)$ & $16.67 \%(58)$ & $18.05 \%(122)$ \\
\hline$\geq 70$ & $4.59 \%(18)$ & $3.33 \%(13)$ & $3.96 \%(31)$ & $7.62 \%(25)$ & $8.91 \%(31)$ & $8.28 \%(56)$ \\
\hline \multicolumn{7}{|l|}{ Ethnicity,\% ( $n)$} \\
\hline Tibetan & $99.74 \%(389)$ & $99.74 \%(391)$ & $99.74 \%(780)$ & $100 \%(328)$ & $100 \%(348)$ & $1000 \%(676)$ \\
\hline Moinba & $0 \%(0)$ & $0.26 \%(1)$ & $0.10 \%(1)$ & $0 \%(0)$ & $0 \%(0)$ & $0 \%(0)$ \\
\hline Others & $0.26 \%(1)$ & $0 \%(0)$ & $0.10 \%(1)$ & $0 \%(0)$ & $0 \%(0)$ & $0 \%(0)$ \\
\hline \multicolumn{7}{|l|}{ Education,\% (n) } \\
\hline $\begin{array}{l}\text { Elementary education and } \\
\text { below }\end{array}$ & $98.46 \%(384)$ & $99.23 \%(389)$ & $97.70 \%(763)$ & $48.60 \%(312)$ & $50.62 \%(325)$ & $99.22 \%(637)$ \\
\hline Middle/high school & $1.28 \%(5)$ & $0.51 \%(2)$ & $0.90 \%(7)$ & $0.62 \%(4)$ & $0.16 \%(1)$ & $0.78 \%(5)$ \\
\hline College and higher & $0 \%(0)$ & $0.26 \%(1)$ & $0.13 \%(1)$ & $0 \%(0)$ & $0 \%(0)$ & $0 \%(0)$ \\
\hline BMI, mean \pm SD & $\begin{array}{l}25.25 \pm \\
7.02\end{array}$ & $26.32 \pm 17.31$ & $\begin{array}{l}25.82 \pm \\
4.36\end{array}$ & $25.13 \pm 11.63$ & $24.45 \pm 4.50$ & $24.78 \pm 8.85$ \\
\hline
\end{tabular}


women, and their mean age (52.79 \pm 8.74 years old $)$ was almost equal to the mean age of men $(51.81 \pm 8.07$ years old). For levels of education, the majority of men and women only received elementary education (97.70\%). The mean BMI of women was greater than that of men, while overweight was indicated for both women and men.

\section{The prevalence of RA in Tibet}

The overall prevalence of RA was $4.86 \%$, and it was more prevalent in women than that in men $(7.14 \%$ vs. $2.56 \%, p=0.005)$. The age-standardized prevalence of RA was $6.30 \%$ (95\% CI $4.20-8.64 \%)$, which was 2.46\%(95\% CI $1.04 \%, 4.10 \%$ )and $9.59 \%$ (95\% CI 5.93\%, $13.77 \%$ ) in men and women, respectively, as shown in Table 2. Meanwhile, the prevalence of women increased with age (Fig. 2). The association of each factor (age, ethnicity, levels of education, and obesity) with the occurrence of RA was analyzed; however, no significant difference was noted.

\section{Discussion}

The current cross-sectional study involved a regional representative sample of the middle-aged and older Tibet inhabitants, and the overall prevalence of RA was estimated to be $6.30 \%$. Although there was a significant difference in age between those who refused to take blood test and those who underwent blood test, the mean age of the former was higher than the latter. Additionally, the prevalence of RA increased with age; therefore, the true prevalence may be higher. This amazing rate, which is close to the highest prevalence of RA (up to $6.80 \%$ ) worldwide [11], is remarkably different from a previously reported rate $(0.28 \%)$ in China [12]. The prevalence in the group of $\geq 45$ years old was remarkably lower than that of the current study (0.74\%). Similarly, the prevalence in both men $(2.46 \%)$ and women $(9.59 \%)$ in our research was higher than that in a previous study $(0.19 \%$ in men and $1.28 \%$ in women, aged > 45 years old) [12]. However, the prevalence of RA in women increased with age, which reached the peak after 60 years old, and that was consistent with previous researches $[6,12]$. A study showed that the prevalence of RA significantly varies geographically [13]. As China is geographically a large country with a multi-ethnic population and substantial regional differences in socioeconomic and hygienic conditions, the result may not represent China as a whole [14]. Since 1983, a great number of studies have been performed in China to investigate the epidemiologic characteristics of RA, with concentration on differences among different regions [5, 15-25]. In those studies, the prevalence of RA ranged from $0.2 \%$ (Shantou) to $0.93 \%$ (Taiwan), which was remarkably lower than our results. However, the main concern of those researches was the prevalence in low altitude areas of the east-central China, and the majority of the participants were Han nationality [26].

A number of scholars pointed out that the prevalence of RA differs in different regions of the world, which indicated that the etiology of this disease could be influenced by both genetic and environmental factors [27]. Tibet is known as the "Third Pole" and is one of the inhabited areas in the globe, highlighting that the geographical condition of Tibet is different from the inland or coastal areas of China [28]. A research pointed out that the people living at high altitudes showed microflora enriched with butyrate-producing bacteria in response to harsh environments, and core microbiota comprised of Prevotella, Faecalibacterium, and Blautia in Tibetans [29]. Moreover, it was reported that the presence of Prevotella is strongly correlated with disease in new-onset untreated rheumatoid arthritis (NORA) patients [30]. Therefore, this may justify the high prevalence of RA in Tibetans. It is noteworthy that almost all the participants examined in the present study were $\mathrm{Ti}$ betans (99.74\%) living in Luoma Town. In addition, Tibet is an isolated area in mainland China, and the highlanders have lived there for generations, which mean they have distinct genetic backgrounds with a lower level of heterozygosity, and a higher level of runs of homozygosity [31]. To our knowledge, $50 \%$ of the risk of RA is attributable to genetic factors [1]. This may explain a remarkably higher prevalence of RA in Tibet compared with that in other areas of China. The prevalence of RA of native American Chippewa Band (6.8\%) is far above the other Americans (1.07\%) [12, 32]. This is not a coincidence, but further study is needed to confirm it.

Our results demonstrated that the prevalence of RA reaches the highest in high altitude areas of Tibet. Therefore, further attention should be paid to the prevention and treatment of RA in Tibet.

\section{Strengths and limitations}

This is the first cross-sectional study concentrating on spreading of RA in the Tibet Autonomous Region. Our

Table 2 The prevalence of rheumatoid arthritis

\begin{tabular}{|c|c|c|c|c|}
\hline \multicolumn{5}{|c|}{ The prevalence of rheumatoid arthritis } \\
\hline & Male & Female & & Overall \\
\hline Crude, \% & $2.56 \%(2.318 \%, 2.82 \%)$ & $7.14 \%(6.44 \%, 7.85 \%)$ & $p=0.005$ & $4.86 \%(4.52 \%, 5.20 \%)$ \\
\hline Age-standardized, \% & $2.46 \%(1.04 \%, 4.10 \%)$ & $9.59 \%(5.93 \%, 13.77 \%)$ & & $6.30 \%(4.20 \%, 8.64 \%)$ \\
\hline
\end{tabular}




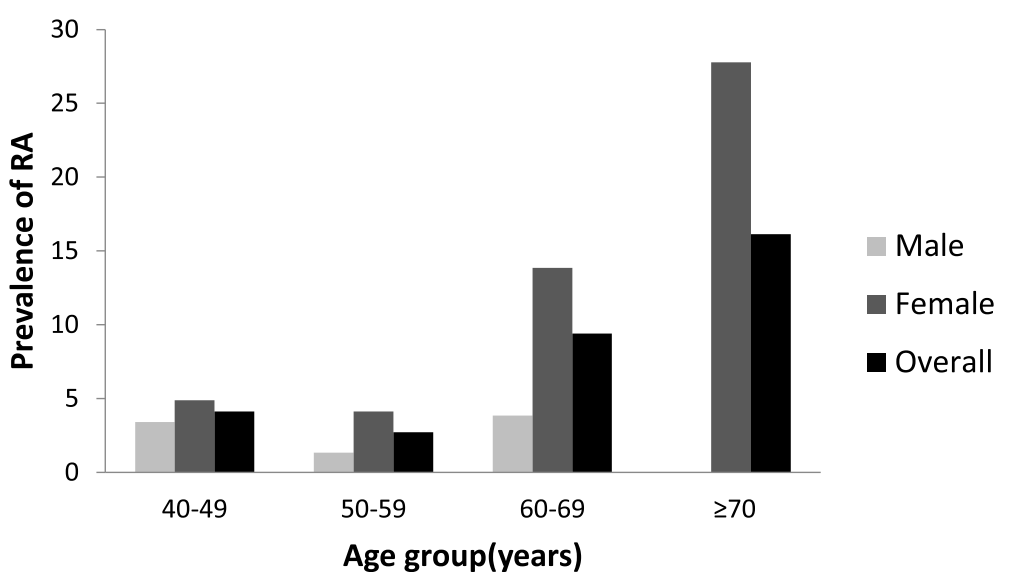

Fig. 2 The prevalence of rheumatoid arthritis (RA) in four age groups

results may provide a reliable reference for future research on RA in Tibet. However, this study contains a number of limitations. Firstly, selection bias may exist because of subjects who refused to take blood samples, and that factor may influence our results. Secondly, although it is concluded that the prevalence of RA is extremely high in Tibetans, we did not assess the mechanism and cause of RA, which is worthy of further investigation.

\section{Conclusions}

This is the first cross-sectional study concentrating on RA status in the Tibet Autonomous Region. Our findings unveiled that the prevalence of RA in Tibetans was the highest in mainland China. Future studies should further investigate the roles of genetic and environmental factors. Besides, further attention should be paid on behalf of the central government of the People's Republic of China to treat RA in the Tibet.

\section{Acknowledgements}

We acknowledge the staff of Luoma town health station and Tibet Autonomous Region People's Hospital, Lhasa People's Hospital and Tibet Center for Disease control and Prevention. We thank the School of Public Health, Peking University for the statistical consultation.

\section{Consent to participate}

Written informed consent was obtained from all participants according to the Declaration of Helsinki.

\section{Authors' contributions}

$H G$ and $J L$ were responsible for the conception and design of the work. QZ, $\mathrm{CL}, \mathrm{YB}$, and $\mathrm{HL}$ acquired the data. QZ, LC and LQ performed data analysis and quality assessment. QZ drafted the article and all authors revised it critically for important intellectual content. The authors read and approved the final manuscript

\section{Funding}

This study was supported by National Natural Science Foundation of China (No. 81672183, 81501919), Peking University People's Research Development Funds (No.2127000091) and Technology Science and Technology Major Projects of Beijing Municipal Science and Technology Commission of China (No. Z181100001818008, D171100003217002, Z171100002717094).
Availability of data and materials

The first author can provide all data.

\section{Ethics approval}

The survey was approved by the Pecking University Health Science Center Ethics Committees.

\section{Consent for publication}

All authors approved the final version to be submitted.

\section{Competing interests}

The authors declare that they have no conflict of interest.

\section{Author details}

${ }^{1}$ Arthritis Clinic \& Research Center, Peking University People's Hospital, Peking University, 11th Xizhimen South Street, Beijing, China. ${ }^{2}$ Arthritis Institute, Peking University, Beijing, China. ${ }^{3}$ Department of Rheumatism, Tibet Autonomous Region People's Hospital, Tibet, China. ${ }^{4}$ Tibet Center for Disease Control and Prevention, No. 21, North Linkuo Road, Chengguan District, Lhasa City 850000, Tibet Autonomous Region Tibet, China.

Received: 16 June 2020 Accepted: 12 August 2020

Published online: 18 August 2020

\section{References}

1. Scott DL, Wolfe F, Huizinga TWJ. Rheumatoid arthritis. Lancet. 2010;376: 1094-108.

2. Malaviya A, Kapoor S, Singh R, Kumar A, Pande I. Prevalence of rheumatoid arthritis in adult population. Rheumatol Int. 1993:13:131-4.

3. Safiri S, Kolahi AA, Hoy D, et al. Global, regional and national burden of rheumatoid arthritis 1990-2017: a systematic analysis of the Global Burden of Disease study 2017. Ann Rheum Dis. 2019:0:1-9.

4. Kalla AA, Tikly M. Rheumatoid arthritis in the developing world. Best Pract Res Clin Rheumatol. 2003;17:863-75.

5. Beasley RP, Bennett PH, Lin CC. Low prevalence of rheumatoid arthritis in Chinese. Prevalence survey in a rural community. J Rheumatol Suppl. 1983; 10:11-5.

6. Qing Yu Zeng, Ren Chen, John Darmawan, et al.: Rheumatic Diseases in China. Arthritis Research \& Therapy 2008, 10:R17.

7. Li S, Wu J, Gong J, Li S. Human footprint in Tibet: Assessing the spatial layout and effectiveness of nature reserves. Sci Total Environ. 2018;621:18-29.

8. Zhang Q, Gong H, Lin C, Liu Q, Baima Y, Wang Y, Lin J. The prevalence of gout and hyperuricemia in middle-aged and elderly people in Tibet Autonomous Region. China: A preliminary study. 2020;99(2):e18542.

9. Kay J, Katherine SU. ACR/EULAR 2010 rheumatoid arthritis classification criteria. Rheumatology. 2012;5:vi5vi9.

10. National Bureau of Statistics. Tabulation on the 2010 population census of thePeople's Republic of China. (China Statistics Press, 2012). 
11. Li R, Sun J, Ren LM, et al. Epidemiology of eight common rheumatic diseases in China: a large-scale cross-sectional survey in Beijing. Rheumatology (Oxford). 2012;51(4):721-9.

12. Harvey J, Lotze M, Stevens MB, et al. Rheumatoid arthritis in a Chippewa Band I. Pilot screening study of disease prevalence. Arthritis Rheum. 1981;24:717 21.

13. Costenbader KH, Chang SC, Laden F, Puett R, Karlson EW. Geographic variation in rheumatoid arthritis incidence among women in the United States. Arch Intern Med. 2008;168(15):1664-70.

14. Zhao J, Mariotti SP, Resnikoff $\mathrm{S}$, et al. Assessment of trachoma in suspected endemic areas within 16 provinces in mainland China. PLoS Nail Trop Dis. 2019 Jun;13(6):e0007531.

15. Chen SL, Zeng QY: The COPCORD study in China [abstract]. In Programme and Abstracts of the 8th Asia Pacific League of Associations for Rheumatology Congress of Rheumatology Melbourne, Australia 1996:s182. 21-26.

16. Sun G, Xia D, Fang H. A survey of incidence of rheumatoid arthritis (RA) and ankylosing spondylitis (AS). Chin J Rehabil Med (Chinese). 1988:3:115-7.

17. Wigley RD, Zhang NZ, Zeng QY, et al. Rheumatic diseases in China: ILARChina study comparing the prevalence of rheumatic symptoms in northern and southern rural populations. J Rheumatol. 1994;21:1484-90.

18. Zhang F, Zhao Y, Ren X. Report on survey of rheumatic diseases in northern very cold area of China. Rheum Dis Integrat Chin Trad Med Moden Med (Chinese). 1992:1:1-4.

19. Qian L, Chen J, He L, Liu R, Dong G. An epidemiological survey and analysis on the rheumatic diseases among peasants in Ningxia frigid high elevation region. Environ Sci (Chinese). 2001:107-9.

20. Lau E, Symmons D, Bankhead C, Macgregor A, Donnan S, Silman A. Low prevalence of rheumatoid arthritis in the urbanized Chinese of Hong Kong. J Rheumatol. 1993;20:1133-7.

21. Chou CT, Pei L, Chang DM, Lee CF, Schumacher HR, Liang MH. Prevalence of rheumatic diseases in Taiwan: a population study of urban, suburban. rural differences. J Rheumatol. 1994;21:302-6.

22. Zeng QY, Chen R, Xiao ZY, Liu Y, Xu J, Wigkey RD. Shantou COPCORD study: stage I. APLAR Bull. 1995;13:74-6.

23. Zhang H, Liu Z, Su H, Zhou H, Xun Y, Jiang X. Epidemiological studies on rheumatoid arthritis and ankylosing spondylitis in rural area of Shandong province. Chin J Rheumatol (Chinese). 1998;2:85-7.

24. Dai S, Han X, Zhao D, Shi Y, Liu Y, Meng J. Prevalence of rheumatic symptoms, rheumatoid arthritis, ankylosing spondylitis, and gout in Shanghai, China: a COPCORD study. J Rheumatol. 2003:30:2245-51.

25. Zang $\mathrm{CH}$, Zeng QY, Li X, Dong H, Zhang A. Epidemiological study of rheumatic diseases in Taiyuan area. Chin Remd Clin (Chinese). 2007;7:597-602.

26. Yao-Jun Xiang - Sheng-Ming Dai: Prevalence of rheumatic diseases and disability in China. Rheumatol Int (2009) 29:481-490.

27. Karami J, Aslani S, Jamshidi A, Garshasbi M, Mahmoudi M. Genetic implications in the pathogenesis of rheumatoid arthritis; an updated review. Gene. 2019;702:8-16.

28. Cuo L, Zhang Y. Spatial patterns of wet season precipitation vertical gradients on the Tibetan Plateau and the surroundings. Sci Rep. 2017;7(1):5057.

29. Lan D, Ji W, Lin B, et al. Correlations between gut microbiota community structure of Tibetans and geography. Sci Rep. 2017:7(1):16982.

30. Scher JU, Sczesnak A, Longman RS, et al. Expansion of intestinal Prevotella copri correlates with enhanced susceptibility to arthritis. Elife. 2013;2:e01202.

31. Lu D, Lou H, Yuan K, et al. Ancestral origins and genetic history of Tibetan highlanders. Am J Hum Genet. 2016;99(3):580-94.

32. Gabriel SE, Crowson CS, O'Fallon WM. The epidemiology of rheumatoid arthritis in Rochester, Minnesota, 1955 1985. Arthritis Rheum. 1999;42:415 20.

\section{Publisher's Note}

Springer Nature remains neutral with regard to jurisdictional claims in published maps and institutional affiliations.

Ready to submit your research? Choose BMC and benefit from:

- fast, convenient online submission

- thorough peer review by experienced researchers in your field

- rapid publication on acceptance

- support for research data, including large and complex data types

- gold Open Access which fosters wider collaboration and increased citations

- maximum visibility for your research: over $100 \mathrm{M}$ website views per year

At $\mathrm{BMC}$, research is always in progress.

Learn more biomedcentral.com/submissions 